\section{A Rapid, Objective Method to Index Leaf Chlorosis in Spinach}

\author{
Jose Reynaldo A. Santos \\ Texas A\&M University Agricultural Research and Extension Center, \\ Uvalde, TX 78801
}

Additional index words. leaf color measurement, disease rating, leaf chlorophyll, chromaticity, color analyzer, Albugo occidentalis, Spinacia oleracea

\begin{abstract}
Chlorophyll extraction (TCHL) and spectrophotometric (CM45) techniques were compared with a visual (VISINDX) method of indexing chlorosis on spinach (Spinacea oferacea $L$.) leaves that show various degrees of white rust (Albugo occidentalis G.W. Wils.) infection. The CM45 method gave a good fit $\left(R^{2}=0.91\right)$ when its readings were regressed against MSINDX ratings. Both regression and cluster analyses indicated that the CM45 method was more efficient than the TCHL method in separating leaves into unique chlorosis severity classes.
\end{abstract}

Spinach cultivars are susceptible to many pathological and nutritional stresses, the symptoms of which are commonly expressed as leaf chlorosis. Plant breeders evaluate spinach for disease resistance by visually indexing each accession for leaf chlorosis relative to a susceptible reference or compared with a chart devised specifically for assessing plant diseases (James, 1971). Whereas visual indexing of leaf color simplifies plant evaluation, it tends to be subjective and results are arbitrary. Recent studies (Marquard and Tipton, 1987; Singha and Townsend, 1989; Yadava, 1986) have shown that using portable color analyzers facilitates leaf chlorophyll content determination. The objective

Received for publication 7 Feb. 1991. Accepted for publication 10 Sept. 1991. Texas Agricultural Experiment Station publication no. TA-26069. The use of trade names in this publication does not imply endorsement of the products names, nor criticism of similar ones not mentioned. The cost of publishing this paper was defrayed in part by the payment of page charges. Under postal regulations, this paper therefore must be hereby marked advertisement solely to indicate this fact. of this study was to compare leaf chlorophyll extraction, a spectrophotometric method, and visual indexing for evaluation of leaf chlorosis in spinach.

Twenty-four leaves from several spinach varieties showing various degrees of chlorosis were randomly sampled from the white rust nursery plots at the Texas A\&M Univ. Agricultural Research and Extension Center at Uvalde. The leaves were numbered and placed abaxial side up on a well-lit laboratory table. Five people independently visually indexed the leaves for chlorosis on a scale where $1=$ no chlorosis and $5=$ severe chlorosis. The five individual scores for each leaf were averaged and used for comparison with the rating indices (VISINDX method) obtained from the two other techniques used. Leaf color of the same set of leaves was read abaxially at three points that were spaced from each other such that each point represented approximately a crosswise one-third section of the leaf. Color was read at each point where chlorosis was visually most severe by means of a ColorMate/ color analyzer (Milton Roy, Rochester, N.Y.) fitted with a $29-\mathrm{mm}$ view insert (CM45 method).
The instrument was preprogrammed to average the readings across those three points. The color analyzer was calibrated using a white reference tile at illuminant $\mathrm{C}$. Illuminant $\mathrm{C}$ is a proposed Commission Internacional de L'Eclairage (CIE) illuminant standard that approximates a bluish light illumination of a cloudy daylight or north daylight $(6774 \mathrm{~K})$. ColorMate/ determined leaf color in CIE chromaticity values $\mathrm{L}^{*}, \mathrm{a}^{*}, \mathrm{~b}^{*}$, where $\mathrm{L}^{*}$ values indicate the lightness or darkness; $a^{*}$ values represent the greenness or redness; and $b^{*}$ values correspond to the yellowness or blueness of an object. These values are convertible to the color values used by Hunter (1975). Thus, given three values and a defined illuminant (light source), it is possible to describe the color of an object accurately. The chromaticity values $\mathrm{L}^{*}, \mathrm{a}^{*}$, and $b^{*}$ were tested for their predictive ability by regressing them, singly or in combination, against the VISINDX values. The ratio $\left(\mathrm{a}^{*}: \mathrm{b}^{*}\right)^{2}$ gave the best fit $\left(R^{2}=0.91\right)$ and had the lowest SE (0.4) (Table 1) and therefore was chosen for comparison with the chlorophyll extraction (TCHL) method. Singha and Townsend (1989) used $\left(a^{*}: b^{*}\right)^{2}$ values effectively to estimate chlorophyll concentration in apple, grape, and peach leaves. Leaf area of each leaf was measured using a digital image analysis system (DIAS; Decagon Devices, Pullman, Wash.). The chlorophyll of each leaf was then extracted in $100 \mathrm{ml}$ of $85 \%$ acetone and absorbance measured using a Spectronic 20 spectrophotometer (Bausch and Lomb, Rochester, N.Y.). Chlorophyll concentration on a freshweight basis was determined using the equation of Robbelen (1957) where total chlorophyll $\left(\mathrm{mg} \cdot\right.$ liter $\left.^{-1}\right)=\left[\left(10.3 \mathrm{~A}_{663}-0.918\right.\right.$ $\mathrm{A}_{644}\left(19.7 \mathrm{~A}_{644}-3.87 \mathrm{~A}_{663}\right]$. Values thus obtained were used with the leaf area measurements to get the chlorophyll concentration in grams per square meter. Regression equations and correlation estimates between readings from CM45 and TCHL methods, and VISINDX were computed using the regression and correlation modules of Stat- 
Table 1. Regression equations of the chromaticity variables $\left(\mathrm{L}^{*}, \mathrm{a}^{*}\right.$, and $\left.\mathrm{b}^{*}\right)$ from spectrophotometric data evaluated for efficiency in predicting the visual rating index (VISINDX) of chlorotic spinach leaves. Model: $\mathrm{Y}=\mathrm{a}+\mathrm{bx}$.

\begin{tabular}{|c|c|c|c|}
\hline $\begin{array}{c}\text { Chromaticity } \\
\text { variable }\end{array}$ & Regression equation & $R^{2}$ & SE \\
\hline $\mathrm{L}^{*}$ & VISINDX $=-4.16+0.17\left(\mathrm{~L}^{*}\right)$ & 0.88 & 0.4 \\
\hline$a^{*}$ & VISINDX $=0.41-0.16\left(a^{*}\right)$ & 0.08 & 1.2 \\
\hline $\mathbf{b}^{*}$ & VISINDX $=-1.65+0.18\left(\mathrm{~b}^{*}\right)$ & 0.84 & 0.4 \\
\hline$a * / b *$ & VISINDX $=7.79+9.10\left(\mathrm{a}^{*} / \mathrm{b}^{*}\right)$ & 0.88 & 0.4 \\
\hline$\left(a^{*} / b^{*}\right)^{2}$ & VISINDX $=5.44-8.32\left[\left(\mathrm{a}^{*} / \mathrm{b}^{*}\right)^{2}\right]$ & 0.91 & 0.4 \\
\hline$a^{2}+b^{2}$ & VISINDX $=0.21+3.26\left(a^{2}+b^{2}\right)$ & 0.72 & 0.6 \\
\hline$\sqrt{a^{2}+b^{2}}$ & VISINDX $=-2.16+0.18\left(\sqrt{a^{2}+b^{2}}\right)$ & 0.77 & 0.6 \\
\hline
\end{tabular}

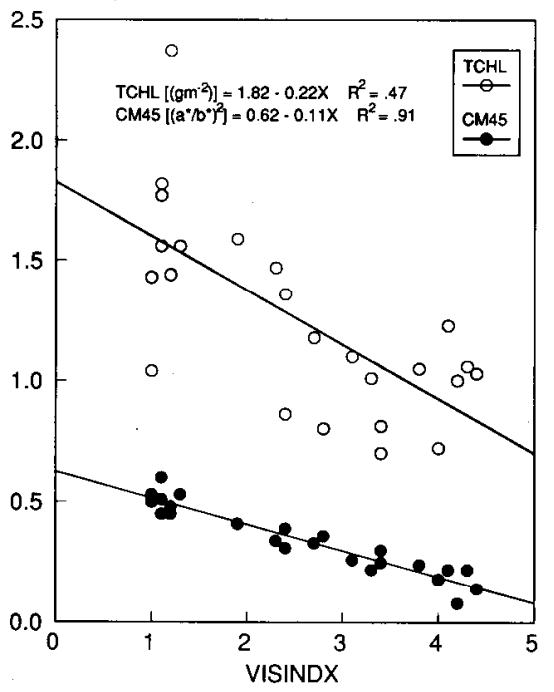

Fig. 1. Plot of the regression equations between leaf chlorophyll concentration (TCHL) and visual indexing (VISINDX), and between spectrophotometric (CM45) and VISINDX. Units for TCHL and CM45 on the y-axis are indicated with their respective regression equations.

graphics (STSC, Rockville, Md.). TCHL, CM45, and VISINDX data were checked for normality, after which a cluster analysis, using the average linkage method (STSC; Milligan, 1980) was performed to assess the relative efficiencies of CM45 and TCHL methods compared to VISINDX. Two separate cluster analysis plots were made: 1) TCHL vs. VISINDX, and 2) CM45 vs. VISINDX. Each analysis was designed to form five unique clusters corresponding to the rating scale used in the VISINDX method. The use of cluster analysis was deemed appropriate as it overcomes the problem of overlapping mean separation groups frequently obtained from conventional statistical techniques (Gates and Bilbro, 1978).

Both CM45 and TCHL decreased linearly with increasing VISINDX (Fig. 1) with the equations describing the regression lines accounting for $91 \%$ and $47 \%$ of the variation in VISINDX, respectively. CM45 and TCHL were significantly correlated $(r=0.62)$ and their slopes tested significantly different using the procedure of Gomez and Gomez (1984). TCHL readings indicated larger deviations $(s=0.29)$ and appeared more effective

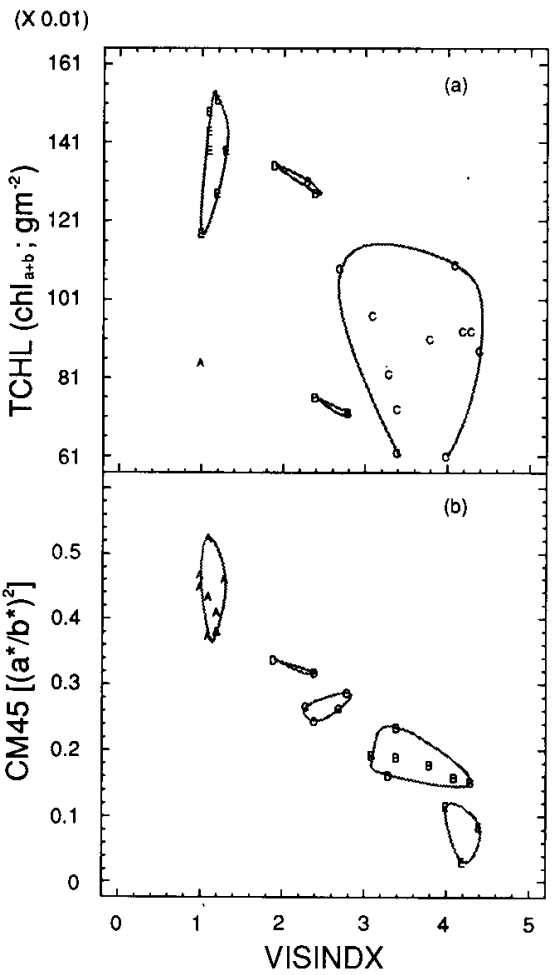

Fig. 2. Cluster analysis plots of (a) leaf chlorophyll concentration (TCHL) vs. visual indexing (VISINDX), and (b) spectrophotometric readings (CM45) vs. VISINDX. Letters (i.e., $\mathrm{A}, \mathrm{B}, . . \mathrm{E})$ within each cluster represent unique grouping of observations and are not related to the indexing method used.

and biased at rating leaves exhibiting either a minimal or severe case of yellowing compared with readings obtained from CM45, which showed consistently smaller deviations $(s=0.14)$ and appeared to be more efficient in evaluating leaves belonging to all severity classes. The first cluster analysis plot (Fig. 2a) shows TCHL and VISINDX methods separating the leaves into two dominant clusters only. For the TCHL method, the first cluster consisted of leaves with TCHL between 0.61 and $1.16 \mathrm{~g} \cdot \mathrm{m}^{-2}$, overlapping two smaller subsets of leaves with TCHL of 0.71 to $0.85 \mathrm{~g} \cdot \mathrm{m}^{-2}$. The second cluster was comprised of leaves with TCHL between 1.18 and $1.54 \mathrm{~g} \cdot \mathrm{m}^{-2}$, overlapping a subset of leaves with TCHL of 1.28 to $1.35 \mathrm{gm}^{-2}$. The VISINDX method had two-cluster overlap for leaves visually rated at 1.0 to 1.3 , and a three-cluster overlap for leaves rated at 1.8 to 4.4 . In the second cluster analysis plot (Fig. 2b) the CM45 method resulted in a clear separation of the leaves into five distinct clusters with no overlapping between adjacent clusters. The VISINDX method was able to discriminate only three clusters with a notable twocluster overlap on leaves visually indexed between 1.8 to 2.8 , and another two-cluster overlap for leaves with rating index falling between 3.1 and 4.5. Leaves with very slight or no chlorosis (VISINDX of $\leq$ 1.4) were easily and efficiently indexed visually.

Of the two methods evaluated for indexing leaf chlorosis, the CM45 method proved superior in terms of separately grouping leaves into distinct severity classes of chlorosis. The resulting objective measurement and ease of operating the color analyzer make it an excellent alternative for the conventional method of visually indexing leaf chlorosis. ColorMate/ 45 is heavy $(\approx 34 \mathrm{~kg})$ and semi-portable compared with the light, portable models, but it has the advantage of having a large measuring aperture that can be fitted with either an 11- or 29-mm view insert; a sample port that can accept very thick $(>1 \mathrm{~cm})$ leaves; and a programmable tolerance limit that can be used to screen out samples that pass or fail those limits. The CM45 method could have a useful application not only in a study such as this, but also in plant breeding research where individuals of a segregating population have to be evaluated separately for disease reaction or nutrient deficiency based on leaf color.

\section{Literature Cited}

Gates, C.E. and J.D. Bilbro. 1978. Illustration of a cluster analysis method for mean separation. Agron. J. 70:462-465.

Gomez, K.A. and A.A. Gomez. 1984. Statistical procedures for agricultural research. Wiley, New York.

Hunter, R.S. 1975. The measurement of appearance. Wiley, New York.

James, C. 1971. A manual of assessment keys for plant diseases. Can. Dept. Agr. Publ. no. 1458.

Marquard, R.D. and J.L. Tipton. 1987. Relationship between extractable chlorophyll and an in situ method to estimate leaf greenness. HortScience 22:1327.

Milligan, G.W. 1980. An examination of the effect of six types of error perturbation on fifteen clustering algorithms. Psychometrika 45:325342.

Robbelen, G. 1957. Untersuchungen an strahleninduzierten Blattfarbmutanten von Arabidopsis thaliana (L) Heynh. Z. Vererbungslehre 88:189252.

Singha, S. and E.C. Townsend. 1989. Relationship between chromaticity values and chlorophyll concentration in apple, grape, and peach leaves. HortScience 24(6):1034.

Yadava, U.L. 1986. A rapid, nondestructive method to determine chlorophyll in intact leaves. HortScience 21:1449-1450. 